\title{
Desenvolvimento de biofilmes à base de xilana e xilana/gelatina para produção de embalagens biodegradáveis
}

\section{Development of xylan and xylan/gelatin biofilms for production of biodegradable packages}

\author{
Camilla Aquino Azevedo de Lucena', Silvana Cartaxo da Costa², Giovanna Rodrigues de Araújo Eleamen², \\ Elisângela Afonso de Moura Mendonça² e Elquio Eleamen Oliveira²*
}

\section{${ }^{1}$ Programa de Pós-graduacão em Ciências Farmacêuticas, Departamento de Farmácia, Centro de Ciências Biológicas e da Saúde - CCBS, Universidade Estadual da Paraíba - UEPB, Campina Grande, PB, Brasil}

'Laboratório de Síntese e Vetorização de Moléculas - LSVM, Departamento de Biologia, Centro de Ciências Biológicas e Sociais Aplicadas - CCBSA, Universidade Estadual da Paraíba - UEPB, Campina Grande, PB, Brasil

*elquioeleamen@yahoo.com.br

\begin{abstract}
Resumo
O objetivo deste trabalho foi desenvolver e caracterizar filmes biodegradáveis à base de xilana extraída de sabugo de milho com potencial uso como uma nova matéria-prima para embalagens biodegradáveis. Para tanto, os filmes foram produzidos através da secagem das dispersões filmogênicas com diferentes concentrações de xilana (150 mg, $300 \mathrm{mg}$, $600 \mathrm{mg}$ ), e glicerol $(5 \%, 10 \%, 15 \%)$, com ou sem adição de gelatina (1000 mg). A caracterização avaliou a morfologia, espessura, solubilidade, biodegradabilidade e opacidade. Os filmes com melhores propriedades foram testados como biocobertura em uvas 'Itália' em duas condições de temperatura: ambiente $\left(25^{\circ} \mathrm{C}\right)$ e refrigerada $\left(4^{\circ} \mathrm{C}\right)$. Os parâmetros de perda de massa e acidez objetivaram avaliar sua eficácia. Os resultados mostraram que os filmes a base de xilana/gelatina apresentaram os melhores aspectos macroscópicos. Além disso, o aumento da concentração de xilana fez decrescer sua solubilidade. Conclui-se que a eficácia dos filmes como bioembalagem foi dependente da concentração de xilana na formulação e do período de avaliação.
\end{abstract}

Palavras-chave: bioembalagens, filmes biodegradáveis, gelatina, xilana.

\begin{abstract}
The aim of this work was to develop and characterize biodegradable films of xylan from corn cobs with potential use as biodegradable package. The films were produced by casting the film-forming dispersions with different amounts of xylan $(150 \mathrm{mg}, 300 \mathrm{mg}$, and $600 \mathrm{mg})$, and glycerol $(5 \%, 10 \%$, and $15 \%)$, with or without gelatin (1000mg). The thickness, solubility, biodegradability, opacity, and morphology of the films were evaluated. The best films were selected to be used for covering grapes 'Italia' stored at two conditions, room temperature $\left(25^{\circ} \mathrm{C}\right)$ and under refrigeration $\left(4{ }^{\circ} \mathrm{C}\right)$. We evaluated the water loss and acidity. The results showed that the xylan/gelatin films present the best macroscopic aspect. Furthermore, increase in the xylan concentration decreased the solubility of the films. We demonstrated that the efficiency of the films was dependent on the xylan content in the formulation and on the period of time used for evaluation.
\end{abstract}

Keywords: biopackage, biodegradable films, gelatin, xylan.

\section{Introdução}

As embalagens para alimentos têm como objetivo proteger produtos contra a contaminação e oxidação, aumentando seu tempo de prateleira ${ }^{[1]}$. Contudo, a degradação dos plásticos sintéticos comumente utilizados para essa finalidade exige muito tempo, e grande parte deles acaba por gerar sobrecarga nos aterros sanitários ${ }^{[2]}$. Os biofilmes aparecem nos últimos anos como um possível substituto para os materiais sintéticos. Esse é um filme fino preparado a partir de produtos naturais, que age como barreira a elementos externos e, consequentemente, pode proteger o produto embalado de danos físicos e biológicos e aumentar a sua vida útil[ ${ }^{[3]}$.

A necessidade de novos materiais para conservação de alimentos principalmente os in natura, como, por 
exemplo, as frutas, tem aumentado devido ao crescimento populacional ${ }^{[4]}$. Alguns filmes obtidos através de produtos renováveis não só são degradados rapidamente após a sua eliminação, mas também podem estender a vida útil dos alimentos, melhorando assim a sua qualidade ${ }^{[2]}$.

Os biofilmes, em geral, são desenvolvidos utilizando polissacarídeos, proteínas, lipídios e derivados ${ }^{[3]}$. Dentre esses, a xilana destaca-se por já ser utilizada na indústria alimentícia e farmacêutica ${ }^{[5]}$, esse polímero é a principal hemicelulose presente na maioria das plantas e responsável por um terço da biomassa renovável disponível na terra ${ }^{[6]}$.

A xilana pode ser extraída de diversos resíduos agrícolas, incluindo a palha de trigo, sabugo e espiga de milho, sorgo, cana-de-açúcar, cascas da produção de amido, entre outros ${ }^{[7,8]}$. Esse heteropolissacarídeo no sabugo de milho representa mais de $60 \%$ dos polissacarídeos da parede celular, compreendendo duas espécies estruturais $\beta$-( $1 \rightarrow 4)$-D-xilopirananas que diferem nos tipos e proporção de unidades de D-glicose na cadeia latera ${ }^{[9,10]}$. A quantidade de xilana no sabugo de milho pode ser considerada a maior dentre todos os subprodutos agrícolas podendo chegar a até $40 \%{ }^{[11]}$

Do ponto de vista estrutural, a xilana de plantas superiores possui como cadeia principal unidades de xilopiranoses unidas por ligações $\beta-(1 \rightarrow 4)^{[12,13]}$. A maioria das xilanas tem outros açúcares nas cadeias laterais, tais como ácido 4-O-metil-D-glicurônico, ácido $O$-acetil-L-arabinose, L-arabinose e ácido D-glicurônico. A quantidade destes açúcares e o tipo de ligação glicosídica, entre eles, e a cadeia principal podem variar muito com a fonte botânica ${ }^{[13]}$.

Existem vários estudos relacionados a filmes biodegradáveis com biopolímeros como a celulose, quitosana e o glúten, mas a literatura relacionada a filmes constituídos de xilana associada a outro polímero ainda é limitada ${ }^{[14]}$. Trabalhos anteriores demonstraram a viabilidade de se produzir filmes de xilana associados a um segundo polímero. Porém, tem se mostrado que a obtenção de filmes contendo apenas xilana apresenta um grande obstáculo tecnológico ${ }^{[8]}$.

Esse trabalho teve como objetivo o desenvolvimento e caracterização físico-química de biofilmes a base de xilana e xilana/gelatina visando aumento da vida útil de alimentos perecíveis, bem como, diminuir os impactos causados por produtos plásticos de difícil degradação no meio ambiente. Para tanto, um estudo sobre as propriedades morfológicas, espessura, solubilidade em água e de biodegradabilidade em solo dos filmes foi realizado. Adicionalmente, os filmes com as melhores propriedades físico-químicas foram testados como bioembalagens no recobrimento de uvas tipo 'Itália'.

\section{Materiais e Métodos}

Xilana extraída do sabugo de milho foi obtida no Laboratório de Síntese e Vetorização de Moléculas (LSVM) da Universidade Estadual da Paraíba de acordo com Oliveira et al. ${ }^{[15]}$. Resumidamente, o sabugo de milho triturado foi lavado com água destilada na proporção de 1L para cada $30 \mathrm{~g}$ de sabugo de milho por 24 horas. Ao final deste processo, a mistura foi filtrada com auxílio de papel filtro e o resíduo seco em estufa a $55^{\circ} \mathrm{C}$. O resíduo seco foi lavado com uma solução de hipoclorito de sódio $1,3 \%$ por 1 hora. Em seguida, foi realizado uma segunda filtração e o resíduo foi novamente seco em estufa. Esse resíduo seco foi tratado com hidróxido de sódio 4\% (v/v). Após 4 horas de extração alcalina, a mistura foi filtrada e o filtrado foi neutralizado com ácido acético glacial. Adicionou-se metanol ao filtrado neutralizado na proporção $1: 1,5(\mathrm{v} / \mathrm{v})$ para a precipitação da xilana. A xilana foi então lavada com metanol e isoprapanol. Ao término da lavagem, a xilana foi filtrada novamente e submetida ao processo de secagem em estufa $\left(55^{\circ} \mathrm{C}\right)$.

Foram utilizados ainda gelatina incolor e sem sabor (Sigma) e glicerol (Vetec).

\subsection{Preparação e caracterização dos filmes}

Os filmes foram produzidos a partir de dispersões aquosas contendo $15 \mathrm{mg} / \mathrm{mL}, 30 \mathrm{mg} / \mathrm{mL}$ e $60 \mathrm{mg} / \mathrm{mL}$ de xilana agitadas por 5 minutos a $50{ }^{\circ} \mathrm{C}$. O glicerol foi adicionado nas concentrações de 5\%,10\% ou 15\% em relação à massa de xilana e essas dispersões distribuídas em placas para secagem em estufa $\left(40^{\circ} \mathrm{C}\right.$ por 24 horas).

Para estudar a influência da utilização de um segundo polímero obteve-se filmes com xilana e gelatina. Primeiramente, $1 \mathrm{~g}$ de gelatina foi solubilizado em $10 \mathrm{~mL}$ de água destilada e agitado por 30 minutos a $55^{\circ} \mathrm{C}$. Em seguida, $10 \mathrm{~mL}$ da dispersão de xilana foram adicionados a $10 \mathrm{~mL}$ de solução aquosa de gelatina. O plastificante foi adicionado em concentrações de 5\%,10\% e 15\% em relação à massa dos polímeros. Essas formulações seguiram o mesmo protocolo de secagem dos filmes de xilana.

As avaliações dos filmes preconizaram suas características morfológicas: ausência de bolha de ar, presença de rachaduras e homogeneidade.

\subsubsection{Espessura dos filmes}

A espessura dos filmes obtidos, medida com um paquímetro digital marca Lee, foi determinada como sendo a média de três medidas aleatórias em diferentes partes do filme.

\subsubsection{Solubilidade dos filmes em água (S)}

A solubilidade dos filmes em água foi determinada em triplicata. Para isto, esses foram cortados em discos de $15 \mathrm{~mm}$ de diâmetro. Determinou-se a porcentagem inicial de matéria seca em estufa $\left(100{ }^{\circ} \mathrm{C}\right.$ por 24 horas). Após pesagem, as amostras foram imersas em água destilada e agitadas por 24 horas em temperatura ambiente. Após esse período, as amostras foram filtradas e secas novamente $\left(100{ }^{\circ} \mathrm{C}\right.$ por 24 horas) para determinar a massa da matéria seca que não se solubilizou em água (Equação 1).

$$
S=\frac{\text { Massa inicial }- \text { Massa final }}{\text { Massa Inicial }} \times 100
$$

\subsubsection{Opacidade}

A opacidade dos filmes foi determinada em duplicata em espectrofotômetro (Spectrum), no qual foram fixados no orifício de passagem da luz UV-Vis para se obter a transmitância do filme na região do visível (500 e $600 \mathrm{~nm})$.

\subsubsection{Biodegradabilidade}

Os filmes foram cortados $(15 \times 15 \mathrm{~mm})$ e pesados em balança analítica. Após a pesagem, as amostras foram colocadas em uma mistura de solo e esterco bovino (1:1) preparado em um recipiente plástico medindo $64 \mathrm{~mm}$ de comprimento, $330 \mathrm{~mm}$ de largura e $85 \mathrm{~mm}$ de profundidade. O solo foi pulverizado com água sempre que preciso para 
manutenção da umidade. No $15^{\circ}$ dia do experimento, o solo foi avaliado para se verificar a degradação dos filmes ${ }^{[16]}$.

\subsubsection{Análise microscópica}

A morfologia dos filmes foi analisada em um microscópio eletrônico de varredura modelo XL 30 ESEM, Philips, a $20 \mathrm{kV}$. Os filmes foram previamente secos em estufa a $40{ }^{\circ} \mathrm{C}$ e recobertos com uma película de ouro sob atmosfera de argônio antes de serem fixados no porta amostra.

\subsection{Cobertura das uvas 'itália'}

Primeiramente, as uvas foram imersas durante 30 minutos em uma solução de água e hipoclorito de sódio $(0,01 \%)$ para higienização. Após esse período, as frutas foram secas à temperatura ambiente. As frutas secas e higienizadas foram divididas em grupos. As frutas do primeiro grupo foram imersas em solução filmogênica durante 1 min e secas a temperatura ambiente (12h). As frutas do segundo grupo (grupo-controle) foram preparadas pelo mesmo método, substituindo a solução filmogênica por água destilada.

\subsubsection{Perda de massa}

As uvas mantidas em temperatura ambiente $\left(25^{\circ} \mathrm{C}\right)$ ou refrigeradas $\left(4^{\circ} \mathrm{C}\right)$ foram pesadas no dia da montagem do experimento e a cada quatro dias (até o vigésimo dia). Os resultados foram expressos em porcentagem considerando-se a diferença entre a massa inicial e a massa obtida a cada intervalo de tempo. A perda de massa foi calculada por meio da Equação $2^{[17]}$.

$$
\% P M=\frac{(M I-M F)}{M I} \times 100
$$

Onde: $\% \mathrm{PM}=$ percentagem de perda de massa parcial acumulada; $\mathrm{MI}=$ massa inicial da amostra em g; $\mathrm{MF}=$ massa final da amostra em $\mathrm{g}$.

\subsubsection{Determinação da acidez titulável}

As análises foram realizadas no dia da montagem do experimento e a cada quatro dias (até o vigésimo) após o cálculo da perda de massa. O suco das uvas foi obtido triturando e filtrando as amostras. Adicionou-se a erlenmeyers, o filtrado e água descarbonada em uma proporção de $1: 5$ e 5 gotas da solução indicadora (fenolftaleína). Foi utilizado $\mathrm{NaOH}$ $0,1 \mathrm{M}$ para a titulação, e os resultados foram expressos em $\%$ de ácido tartárico por $100 \mathrm{~g}$ de fruto.

\subsubsection{Análise estatística}

Os testes de variância (ANOVA) entre as propriedades dos filmes foram realizadas utilizando o programa estatístico (BioEstat 5.0). As diferenças estatísticas entre as médias foram detectadas através do teste de Tuckey $(\mathrm{p} \leq 0,05)$.

\section{Resultados e Discussão}

\subsection{Caracterização macroscópica dos filmes}

Neste trabalho, preparou-se 18 formulações de filmes de xilana e de filmes compostos de xilana/gelatina. Foi observado que o aumento da concentração de xilana nos filmes induziu a variações em suas características macroscópicas, como transparência (menos transparentes) e brilho (menos brilhosos). Essas variações foram observadas tanto nos filmes produzidos apenas com xilana, como nos filmes formados com xilana e gelatina. Ausência de bolhas de ar e aspecto macroscópico homogêneo foram observados em todos os filmes avaliados.

Os filmes de xilana apresentaram-se fragmentados. Esse resultado está de acordo com outros trabalhos descritos na literatura que relacionam à baixa capacidade da xilana pura de formar filmes. Os principais fatores associados a xilana para uma baixa capacidade de formar filmes são o tamanho de sua cadeia polimérica, uma temperatura de transição vítrea elevada e uma baixa solubilidade em água ${ }^{[8,14,18,19]}$. Um fator importante para que haja formação de filmes de xilana é a presença de lignina. Goksu et al. ${ }^{[14]}$ demonstrou que a adição de $1 \%$ de lignina produziu filmes de xilana homogêneos.

Uma abordagem empregada para formar filmes à base de xilana tem sido a preparação de filmes mistos de xilana com um segundo biopolímero. Filmes mistos de xilana e quitosana em diferentes concentrações foram estudados e soluções filmogênicas de xilana com mais de $5 \%$ de quitosana foram capazes de produzir filmes homogêneos ${ }^{[18]}$. Kayserilioglu e colaboradores produziram filmes mistos de xilana com glúten de trigo utilizando até $40 \%$ de xilana na composição dos filmes sem alterar significativamente as propriedades do filme de glúten ${ }^{[8]}$.

Em nosso trabalho escolhemos a gelatina como segundo polímero para produção dos filmes mistos por ser um polímero de baixo custo, baixa toxicidade e amplamente estudado para a produção de filmes. Os filmes contendo xilana e gelatina apresentaram características macroscópicas superiores em relação aos filmes produzidos apenas com xilana. Este resultado é corroborado por dois fatores: (i) alta solubilidade da gelatina em água, atribuída como motivo para boa formação de biofilmes ${ }^{[20]}$; (ii) a estrutura ramificada da xilana contêm diferentes açúcares e substituintes ligados à cadeia principal de xilose. Esses açucares laterais podem interagir com a estrutura da gelatina estabilizando a rede polimérica durante a formação dos filmes ${ }^{[8]}$. Sendo assim, a produção de filmes utilizando a xilana com um segundo polímero pode levar a um incremento nas propriedades físicas do filme.

A adição de plastificantes em soluções filmogênicas induz a modificações na organização tridimensional das moléculas e por conseguinte nas suas propriedades funcionais, como, na redução da sua temperatura de transição vítrea ${ }^{[14]}$. Neste estudo, três diferentes concentrações de glicerol, o agente plastificante mais utilizado em filmes para embalagens alimentícias, foram testadas. Porém, os resultados observados neste experimento, não foram influenciados pela concentração do plastificante utilizado (5-15\%).

\subsection{Propriedades dos filmes}

A Tabela 1 mostra os filmes de xilana com as melhores características macroscópicas, e a Tabela 2 apresenta os dados da espessura e solubilidade em água.

Tabela 1. Composição dos filmes de xilana e gelatina com as melhores propriedades macroscópicas.

\begin{tabular}{cccc}
\hline Filmes & Xilana $(\mathbf{m g})$ & Glicerol $(\mathbf{m g})$ & Gelatina $(\mathbf{m g})$ \\
\hline F1 & 150 & 172 & 1000 \\
F2 & 300 & 195 & 1000 \\
F3 & 600 & 240 & 1000 \\
\hline
\end{tabular}


Tabela 2. Dados de espessura e solubilidade em água dos filmes.

\begin{tabular}{ccc}
\hline Filmes & Espessura (mm) & $\begin{array}{c}\text { Solubilidade em } \\
\text { água(\%) }\end{array}$ \\
\hline F1 & $0,14 \pm 0,01^{\mathrm{a}}$ & $97,37 \pm 1,58^{\mathrm{a}}$ \\
F2 & $0,15 \pm 0,02^{\mathrm{a}, \mathrm{b}}$ & $60,60 \pm 10,93^{\mathrm{b}}$ \\
F3 & $0,21 \pm 0,01^{\mathrm{b}}$ & $52,52 \pm 12,47^{\mathrm{b}}$ \\
\hline
\end{tabular}

Médias com letras iguais na mesma coluna não diferem ao nível de $\mathrm{p} \leq 0,05$.

\subsubsection{Espessura}

A espessura é um parâmetro que influencia as propriedades dos filmes e quando controlada permite a uniformidade do material e a validade das comparações entre suas propriedades ${ }^{[3,4]}$. A espessura dos filmes aumentou com o incremento de xilana nas soluções filmogênicas de 0,14 a 0,21 mm (Tabela 2). Através da análise de variância: um critério ( $\mathrm{p}=0.0343$ ) observou-se diferença significativa entre os filmes F1 e F3 resultado semelhante ao encontrado para filmes de xilana extraída do caule do algodão que variou de 0,29 a $0,38 \mathrm{~mm}^{[14]}$.

\subsubsection{Solubilidade dos filmes em água}

A solubilidade dos filmes é uma propriedade importante para a aplicação de uma película, pois as possibilidades de aplicações podem exigir insolubilidade em água para aumentar a integridade do produto ${ }^{[8]}$. Em alguns casos, como no revestimento de alguns alimentos a solubilização em água antes do consumo do produto pode ser benéfica ${ }^{[4]}$.

A solubilidade dos filmes em água mostrou-se dependente da quantidade de xilana na formulação (Tabela 2). Através da análise de variância verificou-se diferença significativa $(p=0,0029 ; F=19,8849)$ entre $F 1$ e as formulações F2 e F3 que não perderam sua integridade em solução aquosa após o período de $24 \mathrm{~h}$. Esse fenômeno se deve a baixa solubilidade da xilana em água e confirma que a combinação de xilana e gelatina foi capaz de produzir filmes estáveis.

Os resultados encontrados nesse estudo são corroborados com outros trabalhos descritos na literatura para filmes mistos de xilana. Filmes mistos de poli(vinil álcool)/xilana também mostraram solubilidade dependente da proporção de xilana. Com solubilidade de $40 \%$ e $50 \%$ para os filmes de poli(vinil álcool)/xilana (4/1) e poli(vinil álcool)/xilana (1/1), respectivamente ${ }^{[21]}$. Adição de xilana em filmes mistos de glúten de trigo e xilana produzidos e secos em condições ambientes também induziu uma redução da solubilidade dos filmes. No entanto, observou-se um aumento na solubilidade quando os filmes foram secos a $80{ }^{\circ} \mathrm{C}$ e $35 \%$ de humidade relativa. Os autores justificaram está diferença no perfil de solubilidade devido ao aumento da temperatura, que levou a uma melhor interação entre os polímeros ${ }^{[8]}$.

A relação entre a solubilidade em água e a proporção de xilana foi um fator positivo para a preparação dos filmes xilana/gelatina, uma vez que adequando-se a quantidade da xilana é possível produzir filmes com a solubilidade desejada para cada aplicação.

\subsubsection{Opacidade}

As propriedades ópticas dos filmes são parâmetros importantes especialmente em relação ao acondicionamento de produtos, pois uma embalagem plástica com elevado brilho e transparência constitui-se numa ferramenta valiosa para o setor de marketing, que busca sempre uma apresentação estética atrativa do produto $^{[22]}$.

A transmitância de luz dos filmes variou de 33,46 a 74,5\% no comprimento de onda de $500 \mathrm{~nm}$, sendo o menor valor referente à F3 e o maior F1. Já no comprimento de onda de $600 \mathrm{~nm}$ a transmitância variou de 45,58 a $82,28 \%$ para os mesmos filmes. Houve diferença significativa entre todos os filmes estudados, tanto no comprimento de onda de 500nm $(\mathrm{p}=0,001 ; \mathrm{F}=1591,8368)$ como de $600 \mathrm{~nm}(\mathrm{p}=0,0003$; $\mathrm{F}=447,8411$ ). Esse resultado demonstra que a opacidade dos filmes está diretamente ligada à quantidade de xilana incorporada. Esse fator se torna importante para utilização em coberturas, já que filmes que induzam uma grande redução da transparência podem alterar as características visuais do produto final, levando o consumidor a não aceitação do produto.

\subsubsection{Biodegradabilidade}

O processo de biodegradação de filmes é complexo, depende das condições do meio, dos tipos de micro-organismos e da estrutura do polímero propriamente dito ${ }^{[16]}$. A presença de ligações hidrolisáveis ou oxidáveis na cadeia, uma estereoconfiguração correta, um balanço entre hidrofobicidade e hidrofilicidade e certa flexibilidade conformacional são fatores que contribuem para a biodegradação ${ }^{[23,24]}$.

Esse processo consiste na modificação física ou química de um material pela ação de micro-organismos (principalmente fungos e bactérias), influenciada pelo calor, umidade, radiação e nutrientes ${ }^{[16]}$. Várias espécies de bactérias e fungos produzem o conjunto completo de enzimas necessárias que lhes permitem utilizar xilana como fonte de carbono ${ }^{[25]}$.

A biodegradabilidade das amostras foi estudada através da avaliação da perda de massa dos filmes ao longo do tempo ${ }^{[26]}$. Com 15 (quinze) dias da montagem do experimento foi observado que todas as formulações avaliadas haviam sofrido completa degradação. Esse resultado demonstrou que os filmes produzidos com xilana e gelatina apresentaram alta biodegradabilidade, comprovando sua viabilidade no uso como embalagens biodegradáveis. Como os produtos de degradação não apresentam toxicidade ambiental e aliados à rápida degradação em solo, o uso de filmes compostos à base de xilana e gelatina se mostraram como uma promissora matéria-prima para a produção de embalagens não poluentes.

\subsubsection{Análise microscópica}

Com a finalidade de se observar e analisar possíveis rugosidades e imperfeições, os filmes foram observados por microscopia eletrônica de varredura (MEV) (Figura 1). Os três filmes apresentaram resíduos sólidos, possivelmente de xilana. Apesar da presença destas partículas, sua superfície apresentou pouca rugosidade, indicando certa miscibilidade entre xilana/gelatina/glicerol.

\subsection{Cobertura das uvas com biofilme de xilana/gelatina}

As uvas receberam tratamento com diferentes soluções filmogênicas compostas por xilana e gelatina, utilizando as mesmas formulações avaliadas pelos testes de solubilidade e biodegradabilidade (ver Tabela 1). 

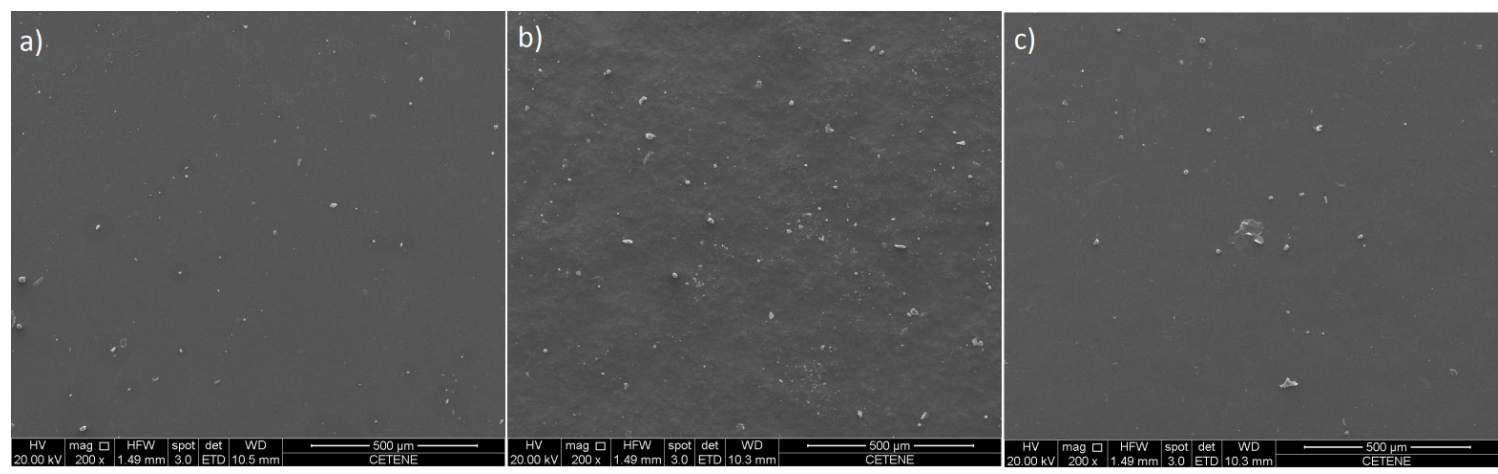

Figura 1. Imagens de MEV dos filmes de xilana/gelatina: (a) F1; (b) F2; e (c) F3.

A perda de massa ocorre principalmente com a perda de água, ou seja, quanto maior a perda de massa, maior a passagem de vapor d'água. Esse fator pode levar principalmente ao murchamento das uvas; sendo assim, a perda de água de produtos armazenados não só resulta em perda de massa, mas também de qualidade. Uma diminuição na perda de massa pode promover um possível aumento da vida de prateleira das frutas ${ }^{[27]}$.

A avaliação da perda de massa das uvas foi feita em temperatura ambiente e refrigerada. Houve perda de massa para todos os tratamentos ao longo do período de armazenamento em temperatura ambiente. Através da ANOVA: fatorial $\mathrm{a} x \mathrm{~b}$ pode-se constatar pequena diferença estatística entre os diferentes tratamentos aos quais as uvas foram submetidas ( $\mathrm{p}=0,0491 ; \mathrm{F}=2,8388$ ).

Para os experimentos desenvolvidos em ambiente refrigerado, foi detectado, através de ANOVA: fatorial a $\mathrm{x} b$ diferença significativa entre $\mathrm{o}$ controle $\mathrm{e}$ as diferentes coberturas de xilana e gelatina durante o período de armazenamento $(p=<0,0001 ; F=25,3133)$. Para saber quais tratamentos diferiram entre si foi realizada a ANOVA: um critério, que não demonstrou diferença entre o controle e os tratamentos, mas somente entre algumas coberturas de xilana e gelatina. A Figura 2 mostra que o filme F3 no $16^{\circ}$ dia de experimento apresentou a menor taxa de perda de massa, porém no $20^{\circ}$ de experimento esta diferença não foi significativa em relação ao controle. Esse fato pode ter ocorrido em virtude de sua solubilidade, pois de acordo com os testes de solubilidade, essa formulação foi a mais resistente à ação da água em relação às outras formulações estudadas.

Os filmes de xilana/gelatina aplicados às uvas, em temperatura ambiente, apresentaram baixa eficiência na contenção da perda de massa no decorrer do período de armazenamento, principalmente entre o $12^{\circ}$ e $16^{\circ}$ dia de experimento. Isso pode ser explicado, pois, biofilmes feitos de polissacarídeos apresentam boa barreira a gases $\left(\mathrm{O}_{2}\right.$ e $\left.\mathrm{CO}_{2}\right)$, mas não a água, isto pode estar relacionado à alta polaridade deste tipo de filme. Além disso, quando presentes em ambientes com alta umidade estão susceptíveis a absorver água do ambiente e se dissolver ${ }^{[28]}$. Resultados similares foram encontrados utilizando biofilmes de gelatina para cobertura de pimentões e de gelana e sorbitol para o revestimento de pêssegos ${ }^{[17,29]}$.

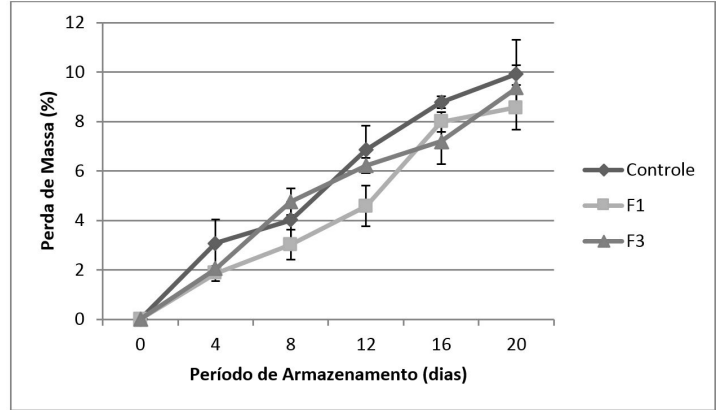

Figura 2. Perda de massa de uvas 'Itália', sem cobertura (controle) e recobertas com filmes utilizando diferentes concentrações de xilana, em função do tempo de armazenamento sob refrigeração. Cada símbolo representa o valor médio de 3 repetições.

\subsubsection{Acidez titulável}

A acidez de um fruto é dada pela presença dos ácidos orgânicos que servem de substratos para respiração e encontram-se dissolvidos nos vacúolos das células tanto na forma livre, como combinada com sais, ésteres e glicosídeos. Os ácidos orgânicos em frutos não contribuem somente para acidez, como também para o aroma característico, devido à volatilidade de alguns componentes. A tendência é haver uma diminuição no teor dos ácidos orgânicos, devido à sua oxidação no ciclo dos ácidos tricarboxilílicos, em decorrência do processo respiratório ou da sua conversão em açúcares; pois, nesta fase, ocorre maior demanda energética pelo aumento do metabolismo ${ }^{[4,17]}$.

A determinação da acidez titulável foi realizada com as mesmas uvas utilizadas na avaliação de perda de massa. AANOVA: fatorial a $\mathrm{x} b$ mostrou diferença significativa entre os tratamentos e o controle tanto em temperatura ambiente $(p=<0,0001 ; \mathrm{F}=18,6989)$, como na refrigerada $(\mathrm{p}=0,0003$; $\mathrm{F}=8,4222)$. E a ANOVA: um critério demonstrou diferença entre o controle e algumas das coberturas nos dias 8 (F1 eF2), 12 (F3) e 16 (F1) essas coberturas especificadas apresentaram acidez mais alta que as uvas do controle (experimento em temperatura ambiente). E diferenças entre o controle e as algumas coberturas foram encontradas nos dias 4 (F1, F2, F3), 12 (F3) e 16 (F1, F2, F3) em ambiente refrigerado. No $20^{\circ}$ dia dos experimentos, sob as duas condições, o 
Tabela 3. Valores médios de acidez titulável (\%) das uvas revestidas com filmes de xilana e gelatina em diferentes concentrações de xilana e glicerol armazenados em temperatura ambiente.

\begin{tabular}{|c|c|c|c|c|c|c|c|c|c|}
\hline \multicolumn{5}{|c|}{ Sem refrigeração } & \multicolumn{5}{|c|}{ Com refrigeração } \\
\hline Dia & Controle & F3 & F2 & F1 & Dia & Controle & F3 & F2 & F1 \\
\hline $\mathbf{0}$ & $0,69^{\mathrm{a}}$ & $0,69^{\mathrm{a}}$ & $0,69^{\mathrm{a}}$ & $0,69^{\mathrm{a}}$ & $\mathbf{0}$ & $0,95^{\mathrm{a}}$ & $0,95^{\mathrm{a}}$ & $0,95^{\mathrm{a}}$ & $0,95^{\mathrm{a}}$ \\
\hline 4 & $0,89^{\mathrm{a}}$ & $0,75^{\mathrm{b}}$ & $0,88^{\mathrm{a}}$ & $0,71^{\mathrm{b}}$ & 4 & $0,91^{\mathrm{a}}$ & $1,08^{\mathrm{b}}$ & $1,18^{\mathrm{c}}$ & $1,08^{b}$ \\
\hline 8 & $0,76^{\mathrm{a}}$ & $0,80^{\mathrm{a}, \mathrm{b}}$ & $0,86^{\mathrm{b}}$ & $0,98^{\mathrm{c}}$ & 8 & $0,96^{\mathrm{a}}$ & $0,98^{\mathrm{a}, \mathrm{b}}$ & $0,94^{\mathrm{a}, \mathrm{c}}$ & $0,94^{\mathrm{a}, \mathrm{c}}$ \\
\hline 12 & $0,84^{\mathrm{a}}$ & $0,94^{\mathrm{b}}$ & $0,70^{\mathrm{c}}$ & $0,81^{\mathrm{a}}$ & 12 & $0,99^{\mathrm{a}}$ & $1,08^{\mathrm{b}}$ & $0,93^{\mathrm{c}}$ & $0,86^{\mathrm{d}}$ \\
\hline 16 & $0,79^{\mathrm{a}}$ & $0,81^{\mathrm{a}}$ & $0,68^{\mathrm{b}}$ & $0,95^{\mathrm{c}}$ & 16 & $0,94^{\mathrm{a}}$ & $1,05^{\mathrm{b}}$ & $1,20^{\mathrm{c}}$ & $1,14^{\mathrm{d}}$ \\
\hline 20 & $0,84^{\mathrm{a}}$ & $0,86^{\mathrm{a}}$ & $0,79^{\mathrm{a}}$ & $0,80^{\mathrm{a}}$ & 20 & $1,26^{\mathrm{a}}$ & $1,01^{\mathrm{b}}$ & $0,90^{c}$ & $1,21^{\mathrm{d}}$ \\
\hline
\end{tabular}

Médias com letras iguais na mesma linha não diferem ao nível de $\mathrm{p} \leq 0,05$.

controle obteve maior acidez quando comparado às uvas revestidas (Tabela 3).

Foi constada uma oscilação nos valores médios de acidez titulável no decorrer do período de avaliação, como citado em outros trabalhos que empregaram metodologia semelhante ${ }^{[17]}$. Esta variação pode ser atribuída às condições de cultivo e ao tipo de uva empregados no estudo ${ }^{[4,30]}$. Além disso, por se tratar de um experimento destrutivo, em cada dia, uma amostra diferente de uvas foi utilizada, o que pode contribuir para a variação nos valores encontrados.

Apesar da oscilação observada no experimento, a análise estatística corrobora com os resultados encontrados no estudo de perda de massa, em que as uvas revestidas apresentam melhores resultados que o controle entre a primeira e segunda semana de estocagem, porém na terceira semana de armazenamento a melhora induzida pelo revestimento com a cobertura de xilana e gelatina desaparece. Esses resultados estão em acordo com os encontrados por Lemos ${ }^{[17]} \mathrm{em}$ estudo com pimentões 'Magali', no qual os pesquisadores encontraram diferença significativa entre os frutos revestidos com coberturas de gelatina e o controle, porém no $20^{\circ}$ dia não houve diferença significativa. A capacidade de proteção das coberturas utilizadas neste estudo pode ser atribuída, em grande parte, à presença da xilana na composição dos filmes, dado que estudos semelhantes empregando gelatina e amido acetilado demonstraram que os filmes não foram eficientes em evitar a redução de ácidos totais nas uvas revestidas ${ }^{[4]}$.

\section{Conclusões}

Neste trabalho, foram preparados 18 filmes à base de xilana e xilana/gelatina. Ficou evidente que os filmes produzidos apenas com o polímero de xilana, mesmo na presença de plastificante, apresentaram falhas na sua estrutura morfológica. No entanto, soluções filmogênicas à base de xilana e gelatina foram capazes de produzir filmes uniformes e homogêneos. Com relação à caracterização, foi observado que o aumento na concentração de xilana altera diretamente as propriedades de solubilidade, opacidade e espessura. Este estudo revelou que os filmes produzidos à base de xilana e gelatina apresentam alta degradabilidade (inferior a 15 dias), podendo ser considerados como uma nova matéria-prima não poluente de interesse na indústria de embalagens. Considerando os testes de revestimento das uvas, observou-se uma melhora nas propriedades das frutas revestidas entre o $8^{\circ}$ e $16^{\circ}$ dia, sendo os melhores resultados obtidos em ambiente refrigerado.
Dessa forma, pode-se concluir que a xilana extraída de sabugos de milho, quando associada à gelatina, foi capaz de produzir filmes e coberturas para as uvas e induzir uma melhora nas propriedades do produto. Estes resultados podem estimular o desenvolvimento de novas pesquisas na extração de xilana em escala industrial a partir de sabugos de milho, gerando valor agregado a este resíduo orgânico e contribuindo para a redução da geração de resíduos.

\section{Agradecimentos}

À PROPESQ-UEPB (projeto número 013/2011) e ao CNPq. Ao FACEPE/CETENE (projeto APQ-0238-4.03/11) pela bolsa de pesquisa e análises de MEV. À professora Eliete Correia dos Santos pela revisão do texto.

\section{Referências}

1. Robertson, G. L. (2009). Food packaging and shelf life: a practical guide. Boca Raton: CRC Press.

2. Xu, Y. X., Kim, K. M., Hanna, M. A., \& Nag, D. (2005). Chitosan-starch composite film: preparation and characterization. Industrial Crops and Products, 21(2), 185-192. http://dx.doi. org/10.1016/j.indcrop.2004.03.002.

3. Henrique, C. M., Cereda, M. P., \& Sarmento, S. B. S. (2008). Características físicas de filmes biodegradáveis produzidos a partir de amidos modificados de mandioca. Ciência e Tecnologia de Alimentos, 28(1), 231-240. http://dx.doi.org/10.1590/S010120612008000100033.

4. Vicentino, S. L., Floriano, P. A., Dragunski, D. C., \& Caetano, J. (2011). Filmes de amidos de mandioca modificados para recobrimento e conservação de uvas. Química Nova, 34(8), 13091314. http://dx.doi.org/10.1590/S0100-40422011000800003.

5. Šimkovic, I., Tracz, A., Kelnar, I., Uhliariková, I., \& Mendichi, R. (2014). Quaternized and sulfated xylan derivative films. Carbohydrate Polymers, 99(0), 356-364. PMid:24274518. http://dx.doi.org/10.1016/j.carbpol.2013.08.075.

6. Prade, R. A. (1996). Xylanases: from biology to biotechnology. Biotechnology \& Genetic Engineering Reviews, 13(1), 101-131. PMid:8948110. http://dx.doi.org/10.1080/02648725.1996.10 647925.

7. Ebringerová, A., \& Heinze, T. (2000). Xylan and xylan derivatives - biopolymers with valuable properties, 1 . Naturally occurring xylans structures, isolation procedures and properties. Macromolecular Rapid Communications, 21(9), 542-556. http:// dx.doi.org/10.1002/1521-3927(20000601)21:9<542::AIDMARC542>3.0.CO;2-7.

8. Kayserilioğlu, B. Ş., Bakir, U., Yilmaz, L., \& Akkaş, N. (2003). Use of xylan, an agricultural by-product, in wheat gluten based biodegradable films: mechanical, solubility and water vapor transfer rate properties. Bioresource Technology, 
87(3), 239-246. PMid:12507862. http://dx.doi.org/10.1016/ S0960-8524(02)00258-4.

9. Ebringerová, A., Hromádková, Z., Alföldi, J., \& Berth, G. (1992). Structural and solution properties of corn cob heteroxylans. Carbohydrate Polymers, 19(2), 99-105. http:// dx.doi.org/10.1016/0144-8617(92)90119-B.

10. Ebringerová, A., Hromádková, Z., Hríbalová, V., \& Mason, T. J. (1997). Effect of ultrasound on the immunogenic corn cob xylan. Ultrasonics Sonochemistry, 4(4), 311-315. PMid:11233814. http://dx.doi.org/10.1016/S1350-4177(97)00041-2.

11. Yang, R., Xu, S., Wang, Z., \& Yang, W. (2005). Aqueous extraction of corncob xylan and production of xylooligosaccharides. LWT - Food Science and Technology, 38(6), 677-682. http:// dx.doi.org/10.1016/j.1wt.2004.07.023.

12. Habibi, Y., \& Vignon, M. R. (2005). Isolation and characterization of xylans from seed pericarp of Argania spinosa fruit. Carbohydrate Research, 340(7), 1431-1436. PMid:15854618. http://dx.doi.org/10.1016/j.carres.2005.01.039.

13. Garcia, R. B., Ganter, J. L. M. S., \& Carvalho, R. R. (2000). Solution properties of D-xylans from corn cobs. European Polymer Journal, 36(4), 783-787. http://dx.doi.org/10.1016/ S0014-3057(99)00133-0.

14. Goksu, E. I., Karamanlioglu, M., Bakir, U., Yilmaz, L., \& Yilmazer, U. (2007). Production and characterization of films from cotton stalk xylan. Journal of Agricultural and Food Chemistry, 55(26), 10685-10691. PMid:18038981. http:// dx.doi.org/10.1021/jf071893i.

15. Oliveira, E. E., Silva, A. E., Júnior, T. N., Gomes, M. C. S., Aguiar, L. M., Marcelino, H. R., Araújo, I. B., Bayer, M. P., Ricardo, N. M. P. S., Oliveira, A. G., \& Egito, E. S. T. (2010). Xylan from corn cobs, a promising polymer for drug delivery: production and characterization. Bioresource Technology, 101(14), 5402-5406. PMid:20171878. http://dx.doi.org/10.1016/j. biortech.2010.01.137.

16. Oliveira, T. M. (2007). Desenvolvimento e avaliação de filme biodegradável de polietileno incorporado de amido de grãode-bico (Cicer arietinum L.). Viçosa: Universidade Federal de Viçosa.

17. Lemos, O. L. (2006). Utilização de biofilmes comestiveis na conservação pós-colheita do pimentão 'Magali R'. Vitória da Conquista: Universidade Estadual do Sudoeste da Bahia

18. Gabrielii, I., Gatenholm, P., Glasser, W. G., Jain, R. K., \& Kenne, L. (2000). Separation, characterization and hydrogelformation of hemicellulose from aspen wood. Carbohydrate Polymers, 43(4), 367-374. http://dx.doi.org/10.1016/S01448617(00)00181-8.

19. Alekhina, M., Mikkonen, K. S., Alen, R., Tenkanen, M., \& Sixta, H. (2014). Carboxymethylation of alkali extracted xylan for preparation of bio-based packaging films. Carbohydrate Polymers, 100(1), 89-96. PMid:24188842. http://dx.doi. org/10.1016/j.carbpol.2013.03.048.
20. Gennadios, A., Weller, C. L., \& Testin, R. F. (1993). Modification of physical and barrier properties of edible wheat gluten-based films. Cereal Chemistry, 70(4), 426-429.

21. Wang, S., Ren, J., Li, W., Sun, R., \& Liu, S. (2014). Properties of polyvinyl alcohol/xylan composite films with citric acid. Carbohydrate Polymers, 103(0), 94-99. http://dx.doi. org/10.1016/j.carbpol.2013.12.030. PMid:24528705.

22. Sakanaka, L. S. (2007). Confecção de filmes biodegradáveis por extrusão de blendas de amido termoplástico e polibutileno succinato co-adipato (PBSA). Londrina: Universidade Estadual de Londrina.

23. Franchetti, S. M. M., \& Marconato, J. C. (2006). Polímeros biodegradáveis - uma solução parcial para diminuir a quantidade dos resíduos plásticos. Química Nova, 29(4), 811-816. http:// dx.doi.org/10.1590/S0100-40422006000400031.

24. Degli-Innocenti, F., Bellia, G., Tosin, M., Kapanen, A., \& Itävaara, M. (2001). Detection of toxicity released by biodegradable plastics after composting in activated vermiculite. Polymer Degradation \& Stability, 73(1), 101-106. http://dx.doi. org/10.1016/S0141-3910(01)00075-1.

25. Uffen, R. L. (1997). Xylan degradation: a glimpse at microbial diversity. Journal of Industrial Microbiology \& Biotechnology, 19(1), 1-6. PMid:9079281. http://dx.doi.org/10.1038/ sj.jim. 2900417.

26. Guohua, Z., Ya, L., Cuilan, F., Min, Z., Caiqiong, Z., \& Zongdao, C. (2006). Water resistance, mechanical properties and biodegradability of methylated-cornstarch/poly(vinyl alcohol) blend film. Polymer Degradation \& Stability, 91(4), 703-711. http://dx.doi.org/10.1016/j.polymdegradstab.2005.06.008.

27. Lemos, O. L., Rebouças, T. N. H., José, A. R. S., Vila, M. T. R., \& Silva, K. S. (2007). Utilização de biofilme comestível na conservação de pimentão 'Magali R' em duas condições de armazenamento. Bragantia, 66(4), 693-699. http://dx.doi. org/10.1590/S0006-87052007000400020.

28. Davanço, T., Tanada-Palmu, P., \& Grosso, C. (2007). Filmes compostos de gelatina, triacetina, ácido esteárico ou capróico: efeito do $\mathrm{pH}$ e da adição de surfactantes sobre a funcionalidade dos filmes. Ciência e Tecnologia de Alimentos, 27(2), 408-416. http://dx.doi.org/10.1590/S0101-20612007000200034.

29. Jacometti, G. A., Meneghel, R. F. A., \& Yamashita, F. (2003). Aplicação de revestimentos comestíveis em pêssego (Prunus persica). Food Science and Technology, 23(1), 95-100. http:// dx.doi.org/10.1590/S0101-20612003000100020.

30. Botelho, R. V. P., Pires, E. J. P., Terra, M. M., \& Carvalho, C. R. L. (2003). Efeitos do thidiazuron e do ácido giberélico nas características dos cachos e bagas de uvas 'niagara rosada' na região de Jundiaí-SP1. Revista Brasileira de Fruticultura, 25(1), 96-99. http://dx.doi.org/10.1590/S0100-29452003000100028.

Enviado: Maio 19, 2015

Revisado: Nov. 01, 2015 Aceito: Fev. 15, 2016 